of TNF inhibitors in axial SpA (axSpA), demonstrating a structural effect is challenging.

Objectives: To compare 2 yrs of radiographic sacroiliac joint (SIJ) changes in pts receiving etanercept (ETN) in a clinical trial to similar pts not receiving biologics in a cohort study.

Methods: Pts had recent onset non-radiographic (nr)-axSpA fulfilling ASAS criteria. Study group: pts receiving ETN $50 \mathrm{mg}$ once weekly for 2 yrs in EMBARK (NCT01258738). Control group: pts in an ongoing longitudinal cohort study not receiving biologics for 2 yrs (DESIR, NCT01648907). Outcome measure: change in x-ray SIJ score per mNY criteria (0-4 per SIJ). X-rays were read by 3 experienced readers unaware of image chronology and pt group. Primary endpoint: change (mean of 3 readers) in total SIJ score $(-8$ to +8$)$. Binary endpoints: (1) shift from baseline (BL) $\mathrm{mNY}+$ to wk-104 mNY- and vice versa; (2) change in SIJ score $\geq 1$ (left or right SIJ); (3) change in SIJ score $\geq 1$ in $\geq 1$ SIJ, with change from 0 to 1 and from 1 to 0 considered no change. Treatment effect was analyzed without and with adjustment for the baseline $(\mathrm{BL})$ covariates of sex, symptom duration, smoking status, HLA-B27 status, ASDAS-CRP, SPARCC MRI SIJ score, and SIJ radiography score.

Results: At BL, the control (DESIR, N=197) and ETN (EMBARK, N=164) cohorts differed significantly in all covariates listed above. The difference in change in total SIJ score for control vs ETN, adjusted for covariates, was small but significant: least-squares mean $(95 \% \mathrm{Cl})$ : $0.08(-0.03,0.20)$ vs $-0.14(-0.26,-0.01) ; p=0.008$. The table presents $\mathrm{x}$-ray changes. When adjusted for covariates, the mean difference between control and ETN was significant for 2 of the 3 binary endpoints (table).

Conclusions: This analysis confirms the slow rate of radiographic SIJ progression over 2 yrs in nr-axSpA. The observed data suggest a lower rate of progression with ETN than without a TNF inhibitor.

Disclosure of Interest: M. Dougados Grant/research support from: Pfizer, Abbvie, UCB, Merck, Lilly, Sanofi, Consultant for: Pfizer, Abbvie, UCB, Merck, Lilly, Sanofi, W. P. Maksymowych Grant/research support from: AbbVie, Pfizer, Sanofi, Consultant for: AbbVie, Amgen, Eli Lilly, Janssen Pharmaceutica, L.P, Novartis, Pfizer, Sanofi, UCB, R. Landewe Grant/research support from: Abbott, Amgen, Centocor, Novartis, Pfizer, Roche, Schering-Plough, UCB, Wyeth, Consultant for: Abbott/Abbvie, Ablynx, Amgen, Astra-Zeneca, BMS, Celgene, Janssen (formerly Centocor), Galapagos, GSK, Novartis, Novo-Nordisk, Merck, Pfizer, Roche, Schering-plough, TiGenix, UCB, Wyeth, Employee of: Is a director of Rheumatology Consultancy BV, A. Molto Grant/research support from: Pfizer, UCB, Consultant for: Abbvie, BMS, MSD France- Merck, Pfizer, UCB, P. Claudepierre Grant/research support from: Pfizer, Roche-Chugai, MSD, Consultant for: Abbvie, BMS, Celgene, Janssen, Novartis, Merck, Pfizer, Roche, UCB, M. de Hooge: None declared, R. G. Lambert Consultant for: Bioclinica, R. Bonin Shareholder of: Pfizer, Employee of: Pfizer, J. Bukowski Shareholder of: Pfizer, Employee of: Pfizer, $\mathrm{H}$. Jones Shareholder of: Pfizer, Employee of: Pfizer, I. Logeart Shareholder of: Pfizer, Employee of: Pfizer, R. Pedersen Shareholder of: Pfizer, Employee of: Pfizer, A. Szumski Employee of: InVentiv Health, B. Vlahos Shareholder of: Pfizer, Employee of: Pfizer, D. van der Heijde Consultant for: AbbVie, Amgen, Astellas, AstraZeneca, BMS, Boeringer Ingelheim, Celgene, Daiichi, Eli-Lilly, Galapagos, Gilead, Janssen, Merck, Novartis, Pfizer, Regeneron, Roche, Sanofi, UCB, Employee of: Director of Imaging Rheumatology bv. DOI: 10.1136/annrheumdis-2017-eular.1860

\section{THU0383 INCIDENCE OF UVEITIS IN NON-STEROIDAL ANTI-INFLAMMATORY DRUGS VERSUS TUMOR NECROSIS FACTOR INHIBITORS USERS AMONG PATIENTS WITH ANKYLOSING SPONDYLITIS: A RETROSPECTIVE COHORT STUDY}

M.J. Kim, E.E. Lee, E.Y. Lee, Y.W. Song, E.B. Lee. Division of Rheumatology, Department of Internal Medicine, Seoul National University Hospital, Seoul, Korea, Republic Of

Background: Uveitis associated with ankylosing spondylitis (AS) often recurs and may lead to ocular complications. It remains to be known whether non-steroidal anti-inflammatory drugs (NSAIDs) or TNF inhibitors (TNFi) is more effective in reducing the recurrence of uveitis in patients with AS.

Objectives: To evaluate the effect of NSAIDs and TNFi on preventing recurrence of uveitis in patients with AS.

Methods: This retrospective cohort study included 1061 patients diagnosed with AS at Seoul National University Hospital between January 2004 and December 2015. Patients' clinical factors and laboratory findings were collected from the patients' electric medical records. Patients were divided into those who were treated with NSAIDs $(n=623)$ or TNFi $(n=438)$ which included etanercept, adalimumab, infliximab and golimumab. The incidence rates of new-onset uveitis during each treatment was compared using Cox proportional hazard model after adjusting age, sex, disease duration, history of uveitis, smoking status, ESR, CRP, and HLA-B27. Propensity-score matched comparison was also performed as sensitivity analysis ( $n=168$ in the TNFi group and $n=168$ in the NSAID group). Results: Among the 1061 patients, those in the TNFi group had longer disease duration (11.75 \pm 7.14 vs $6.22 \pm 4.42$ years), higher ESR, CRP level $(40.97 \pm 33.87$ vs $23.32 \pm 22.09 \mathrm{~mm} / \mathrm{h}, 2.69 \pm 3.41$ vs $1.12 \pm 1.93 \mathrm{mg} / \mathrm{L}$, respectively) and higher proportion of patients who had previous history of uveitis before the treatment (22.4 vs $15.4 \%)$. The incidence rates of uveitis were $3.60(95 \% \mathrm{Cl} 2.97$ to 4.42$)$ per 100 person-year in the NSAID group and 6.03 (95\% Cl 5.15 to 7.04$)$ per 100 person-year in the TNFi group. The adjusted hazard ratio for the new-onset uveitis during the treatment in the TNFi group versus the NSAID group was 1.28 (95\% $\mathrm{Cl} 0.80$ to 2.06) ( $p=0.304)$. When compared with NSAID group, etanercept group showed higher incidence of uveitis than the other TNFi: etanercept (HR 1.96 [1.41 to 2.74]), adalimumab (HR 0.65 [0.40 to 1.05]), infliximab (HR 0.50 [0.22 to 1.14]) and golimumab (HR 0.79 [0.25 to 2.50]). The propensity score-matched population was also consistent with the crude comparison between NSAID group and TNFi group (HR 1.29 [0.73 to 2.28]) $(p=0.388)$.

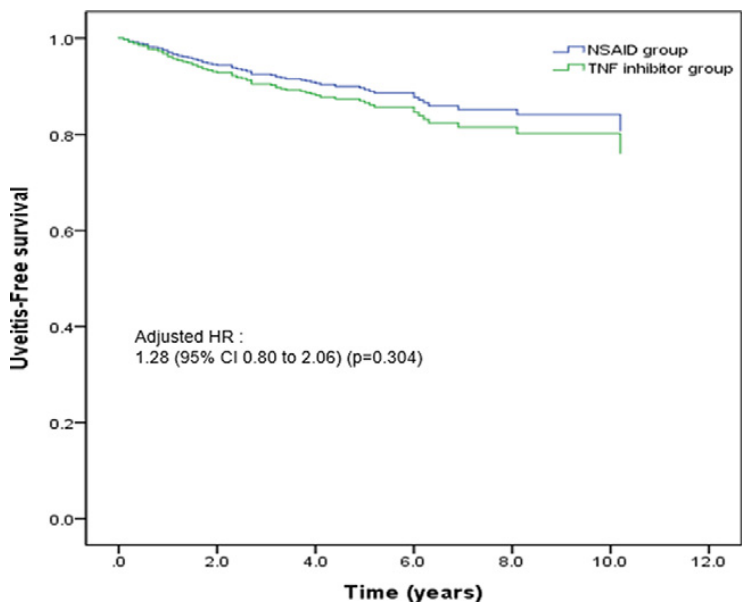

Conclusions: The effect of TNFi on reducing the incidence of uveitis is comparable to NSAIDs in patients with AS. Uveitis occurred more commonly with treatment with etanercept compared with the other treatments.

Disclosure of Interest: None declared

DOI: 10.1136/annrheumdis-2017-eular.3424

\section{THU0384 THE EFFECT AND SAFETY OF YISAIPU (YISAIPU) IN THE TREATMENT OF PATIENTS WITH NONRADIOGRAPHIC AXIAL SPONDYLOARTHRITIS IN CHINA}

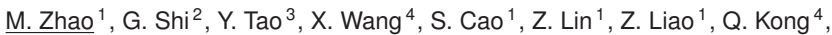
J. Gu ${ }^{1} .{ }^{1}$ Rheumatology department, The Third Affiliated Hospital of Sun Yat-sen University, Guangzhou; ${ }^{2}$ Rheumatology department, The First Affiliated Hospital of Xiamen University, Xiamen; ${ }^{3}$ Rheumatology department, The Second Affiliated Hospital of Guangzhou Medical University; ${ }^{4}$ Radiology department, The Third Affiliated Hospital of Sun Yat-sen University, Guangzhou, China

Background: Axial spondyloarthritis (axSpA) is a chronic inflammatory disease, which includes AS and nr-axSpA. Anti-TNF- $\alpha$ agents, such as Yisaipu (Yisaipu) are frequently used in nr-axSpA patients in China, but the related data is limited. Objectives: The aim of this research is to assess the efficacy and safety of Yisaipu in the treatment of patients with nr-axSpA in China.

Methods: The inclusion of study population consisted of 150 patients who met the ASAS criteria for axial SpA but not the modified New York radiographic criteria for AS, had a score of $\geq 4$ on the BASDAI or a score of $\geq 2.1$ on the ASDAS-CRP and had been treated unsuccessfully with $\geq 1$ NSAIDs for 4 -week. Patients were assigned to receive Yisaipu (made in China) $50 \mathrm{mg} /$ week and continued background NSAID treatment for 24 weeks (open-label study). At week 24 , the

Abstract THU0382 - Table 1. Observed Radiographic Changes from BL to Week 104

\begin{tabular}{|c|c|c|c|c|c|}
\hline Endpoint & Cohort & $\begin{array}{l}\text { Improved } \\
\mathrm{n} / \mathrm{N}(\%)\end{array}$ & $\begin{array}{c}\text { Worsened } \\
\mathrm{n} / \mathrm{N}(\%)\end{array}$ & $\begin{array}{l}\text { Mean Difference }{ }^{\star} \\
(95 \% \mathrm{Cl})^{\dagger}\end{array}$ & $\begin{array}{c}\text { Mean differences (Control - ETN) } \\
(95 \% \mathrm{Cl})\end{array}$ \\
\hline mNY criteria & $\begin{array}{l}\text { Control } \\
\text { ETN }\end{array}$ & $\begin{array}{l}3 / 193(1.6) \\
4 / 161(2.5)\end{array}$ & $\begin{array}{l}6 / 193(3.1) \\
1 / 161(0.6)\end{array}$ & $\begin{array}{l}1.6 \%(-1.5,4.6) \\
-1.9 \%(-4.6,0.9)\end{array}$ & $\begin{array}{l}3.4 \%(-0.7,7.5)^{\dagger} \\
4.7 \%(-0.5,9.9)^{\ddagger}\end{array}$ \\
\hline$\Delta \geq 1$ grade in $\geq 1 \mathrm{SIJ}$ & $\begin{array}{l}\text { Control } \\
\text { ETN }\end{array}$ & $\begin{array}{l}21 / 193(10.9) \\
19 / 161(11.8)\end{array}$ & $\begin{array}{c}36 / 193(18.7) \\
16 / 161(9.9)\end{array}$ & $\begin{array}{l}7.8 \%(0.1,15.4) \\
-1.9 \%(-9.1,5.4)\end{array}$ & $\begin{array}{c}9.6 \%(-0.9,20.2)^{\dagger} \\
18.2 \%(5.6,30.9)^{\ddagger \S}\end{array}$ \\
\hline$\Delta \geq 1$ grade in $\geq 1 \mathrm{SIJ} ; \Delta$ from 0 to 1 and 1 to 0 considered no $\Delta$ & $\begin{array}{l}\text { Control } \\
\text { ETN }\end{array}$ & $\begin{array}{l}16 / 193(8.3) \\
15 / 161(9.3)\end{array}$ & $\begin{array}{c}29 / 193(15.0) \\
14 / 161(8.7)\end{array}$ & $\begin{array}{l}6.7 \%(-0.1,13.5) \\
-0.6 \%(-7.2,6.0)\end{array}$ & $\begin{array}{c}7.4 \%(-2.1,16.8)^{\dagger} \\
16.4 \%(5.1,27.8)^{\ddagger \S}\end{array}$ \\
\hline
\end{tabular}

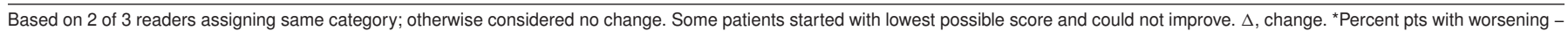
percent pts with improvement. ${ }^{\dagger}$ One-way ANOVA. ${ }^{\ddagger}$ Adjusted for covariates listed in Methods. ${ }^{\S} P=0.005$. 
primary efficacy end point was the improvement of ASDAS-CRP. Secondary end points included ASAS 20, ASAS 40, ASAS 5/6, ASAS partial remission and BASDAI. Safety was evaluated during scheduled visits.

Results: 123 patients with active nr-axSpA were enrolled between April 19, 2014, and July 10,2015 . The mean age of the $123 \mathrm{nr}-\mathrm{SpA}$ patients was $(25.3 \pm 5.9)$ years. The ASDAS-CRP and BASDAI decrease from $2.7 \pm 0.9$ to $0.7 \pm 0.4$, from $4.5 \pm 1.5$ to $0.9 \pm 0.8$, respectively between weeks 0 and 24 . The patients achieved the ASDAS-CRP $<2.1$ was $96.7 \%$. ASDAS-CRP major and important improvement were achieved by $41.4 \%, 79.8 \%$, respectively at weeks 24 . ASAS 20 , ASAS 40 , ASAS5 $/ 6$ and ASAS partial remission were achieved by $75.0 \%, 54.8 \%$, $64.5 \%, 89.3 \%$, respectively at weeks 24 . Yisaipu-treatment was associated with statistically significant improvements in all parameters, including BASFI, BASMI, PGA, PhGA, ESR and CRP concentrations. Most adverse events in the open-label phase were mild or moderate in severity.

Conclusions: Yisaipu was effective and well-tolerated during the 24-week study period and was associated with a significant improvement in the signs and symptoms of active $\mathrm{nr}-\mathrm{axSpA}$

Disclosure of Interest: None declared

DOI: 10.1136/annrheumdis-2017-eular.3846

\section{THU0385 ASSESSMENT OF RELATIONSHIP BETWEEN BELIEFS' ABOUT MEDICINES AND TREATMENT ADHERENCE IN ANKYLOSING SPONDYLITIS PATIENTS}

M. Cinar ${ }^{1}$, F.I. Cinar ${ }^{2}$, E. Tekgoz ${ }^{1}$, R. Horne ${ }^{3}$, S. Yilmaz ${ }^{1} .{ }^{1}$ Department of Internal Medicine, Division of Rheumatology, University of Health Sciences, Gulhane Medical Faculty; ${ }^{2}$ Gulhane School of Nursing. University of Health Sciences, Ankara, Turkey; ${ }^{3}$ UCL School of Pharmacy, Centre for Behavioural Medicine, University College, London, United Kingdom

Background: Ankylosing spondylitis (AS) is a chronic disease requiring longterm treatment. Patients' beliefs about medicines and treatment may affect their treatment adherence and treatment success.

Objectives: In this study, we aimed to investigate the relationship between beliefs about medicines and treatment adherence in AS patients.

Methods: This cross-sectional study was conducted in a single tertiary rheumatology clinic. One hundred and fifty three AS patients were enrolled to the study. Socio-demographic and medical characteristics of the patients were recorded to a patient interview form. In order to evaluate the general and personal views of the patients about drugs, the Turkish Translation of the Beliefs about Medicines Questionnaire (BMQ-T) (Cinar et al in 2016) was used. According to this survey, the beliefs about medicines are composed of the following sections: Specific Necessity, Specific Concerns, General Overuse and General Harm. Medication adherence was assessed by using the Morisky Green Levine Medication Adherence Scale (MGLS) (1986). Adherence was measured on a scale of 0 to 4 , in which higher scores represent lower medication adherence and vice versa. Patients who reported a score of 0 on the MGLS were classified as adherent. All other patients were classified as nonadherent. Categorical variables were compared with Chi-square test, while continuous variables were compared with independent samples $t$ test. To evaluate potential risk factors for non adherence, logistic regression method was used.

Results: The mean age of the patients was $35.15 \pm 8.19$ years. The mean time from first symptom (disease duration) was $10.0 \pm 6.1$ years. The vast majority of the patients $(n=145 ; 94.8 \%)$ were male. One hundred patients $(65.4 \%)$ were using NSAIDs and 83 patients $(54.2 \%)$ were using anti-TNF. According to the MGLS scores, $56(36.6 \%)$ patients were compatible with treatment, and 97 patients $(63.4 \%)$ were found to be incompatible with the treatment. As the BMQ-T-Specific Necessity scores increased, drug compliance was also increased $(\mathrm{p}=0.006)$, on the other hand, as the BMQ-T-Specific Concerns, BMQ-T-General Overuse and BMQ-T-General Harm scores increased, drug compliance was decreased $(p=0.023,0.002,<0.001$, respectively). There were significant positive correlations between Specific Concerns $(p=0.002)$, General Overuse $(p=0.031)$ and General Harm $(p=0.024)$ score levels with the increase in patients' BASDAI score. While there was significant correlation between the disease duration and the General Overuse scores in the negative direction $(p=0.016)$, there was significant correlation between the disease duration and the Specific Necessity scores in the positive direction $(\mathrm{p}=0.002)$. As 1 unit increase in the BMQ-T-Specific Necessity score decreased the risk of treatment nonadherence by 0.38 fold, on the other hand, 1 unit increase in the BMQ-T-General Harm score raised the risk to 3.21 .

Conclusions: In our study, the belief of AS patients about the necessity of treatment they were using, found to increase treatment adherence, while harm potential of the treatment was decreasing the adherence. In other words, to enhance the treatment adherence of AS patients, it is essential to convince the patients about the necessity of treatment and relieve the anxiety they carry about potential adverse effects.

Disclosure of Interest: None declared

DOI: 10.1136/annrheumdis-2017-eular.4091

\section{THU0386 USE OF BIOLOGICS AND NSAIDS IN TREATING PATIENTS WITH AXIAL SPONDYLOARTHRITIS IN THE US-BASED CORRONA PSORIATIC ARTHRITIS/SPONDYLOARTHRITIS (PSA/SPA) REGISTRY}

P.J. Mease ${ }^{1}$, D. van der Heijde ${ }^{2}$, C. Karki ${ }^{3}$, M. Liu ${ }^{3}$, R. Pandurengan ${ }^{3}$, Y. Park ${ }^{4}$ J.D. Greenberg $3,5 .{ }^{1}$ Seattle Rheumatology Associates, Seattle, WA, United States; ${ }^{2}$ Leiden University Medical Center, Leiden, Netherlands; ${ }^{3}$ Corrona, LLC, Southborough, MA; ${ }^{4}$ Novartis, East Hanover, $\mathrm{NJ} ;{ }^{5}$ New York University School of Medicine, New York, NY, United States

Background: Axial spondyloarthritis (axSpA) is a chronic inflammatory disease affecting the sacroiliac joints and spine. Treatment primarily consists of first-line nonsteroidal anti-inflammatory drugs (NSAIDs) and/or biologic therapy when disease activity persists despite NSAID therapy. Although many studies have evaluated the efficacy of these treatments, there are few studies that have characterized NSAIDs and/or biologic therapy among patients with axSpA in the United States.

Objectives: To characterize patients with axSpA treated with NSAIDs only, biologics only, or both NSAIDs and biologics at the time of enrollment in the US-based Corrona PsA/SpA Registry.

Methods: This study included all patients with axSpA diagnosed by the rheumatologist aged $\geq 18$ years enrolled in the Corrona Registry between March 2013 and September 2016 who were treated with NSAIDs only, biologics only, or both NSAIDs and biologics at the time of enrollment (baseline). Patients fulfilled the Assessment of SpondyloArthritis international Society classification criteria. ${ }^{1}$ Demographics, clinical characteristics, disease activity measures and treatment history were collected at enrollment and described for each group.

Results: As of September 2016, 359 patients with axSpA met the study inclusion criteria; at baseline, 224 patients $(62.4 \%)$ were receiving NSAIDs (92 [25.6\%] with NSAIDs only and 132 [36.8\%] with both NSAIDs and biologics) and 135 patients $(37.6 \%)$ were receiving biologics only. Baseline characteristics were similar across all treatment subgroups with regards to age, race and body mass index. Fewer females were treated with biologics (with/without NSAIDs) compared to the NSAIDs only group. At baseline, patients treated with NSAIDs or both NSAIDs and biologics were older, had longer duration of disease with worse disease activity (measured by ASDAS and BASDAI), functional impairment (BASFI and HAQ-DI) and had worse pain and fatigue compared to those treated with biologics only (Table 1). $88-96 \%$ of patients receiving biologics (with or without NSAIDs) had prior biologic use compared to only $25 \%$ of NSAIDs only group. Patients treated with biologics only reported decreased percentage of impairment while working, overall work impairment and activity impairment at baseline compared with patients treated with NSAIDs only and both NSAIDs and biologics.

Table 1. Baseline clinical and patient-reported characteristics of patients with axSpA in the Corrona PsA/SPA Registry stratified by NSAID and biologic use

\begin{tabular}{|c|c|c|c|}
\hline Characteristics* & $\begin{array}{c}\text { NSAIDs } \\
\text { Only } \\
(n=92)\end{array}$ & $\begin{array}{c}\text { Biologics } \\
\text { Only } \\
(n=135)\end{array}$ & $\begin{array}{l}\text { NSAIDs and } \\
\text { Biologics } \\
(n=132)\end{array}$ \\
\hline Age, years & $48.6(15.0)$ & $46.1(13.6)$ & $48.1(13.2)$ \\
\hline White, n (\%) & $81(91.0)$ & $120(93.0)$ & $118(92.9)$ \\
\hline Male, $\mathrm{n}(\%)$ & $53(58.9)$ & $88(65.7)$ & $91(70.5)$ \\
\hline BMI, $\mathrm{kg} / \mathrm{m}^{2}$ & $29.4(6.1)$ & $29.7(7.1)$ & $28.7(6.1)$ \\
\hline Disease duration, years & $18.3(13.0)$ & $16.1(12.7)$ & $19.2(11.5)$ \\
\hline History of prior cSDMARD use, $n(\%)$ & $23(25.0)$ & $55(40.7)$ & $47(35.6)$ \\
\hline History of prior biologic use, $\mathrm{n}(\%)$ & $24(26.1)$ & $130(96.3)$ & $117(88.6)$ \\
\hline ASDAS-CRP & $\frac{24(20.1)}{2.1(0.7)}$ & $\frac{(100.8)}{1.9(0.8)}$ & $\frac{10.0}{2.1(0.9)}$ \\
\hline BASDAI $(0-10)$ & $4.4(2.5)$ & $3.7(2.5)$ & $4.4(2.6)$ \\
\hline $\operatorname{BASFI}(0-10)$ & $3.7(2.9)$ & $3.1(2.8)$ & $3.5(2.9)$ \\
\hline Patient pain (VAS 0-100) & $49.9(29.5)$ & $37.3(28.7)$ & $44.4(30.5)$ \\
\hline Patient-reported fatigue (VAS 0-100) & $47.1(29.4)$ & $45.7(28.6)$ & $\frac{44.4(30.9)}{49.9(30.7)}$ \\
\hline Morning stiffness. $n(\%)$ & $88(95.7)$ & $\frac{40.1(20.0)}{114(84.4)}$ & $\frac{43.0(8.6)}{117(88.6)}$ \\
\hline $\mathrm{HAQ}-\mathrm{DI}(0-3)$ & $0.7(0.6)$ & $\frac{0.5(0.6)}{0.9}$ & $0.6(0.7)$ \\
\hline \multicolumn{4}{|l|}{ WPAI-GH } \\
\hline Absenteeism (\% Work time missed) & $5.3(17.8)$ & $5.5(15.5)$ & $7.5(18.6)$ \\
\hline Presenteeism (\% Impairment while working) & $28.7(28.0)$ & $21.7(24.3)$ & $29.4(26.2)$ \\
\hline Work Productivity (\% Overall work impairment) & $26.1(26.4)$ & $22.8(25.7)$ & $32.5(37.7)$ \\
\hline Activity Impairment (\% Activity impairment) & $41.0(29.9)$ & $31.4(30.7)$ & $39.8(31.6)$ \\
\hline \multicolumn{4}{|c|}{$\begin{array}{l}\text { ASDAS-CRP, Ankylosing Spondylitis Disease Activity Score using C-reactive protein; BASDAI, Bath Ankylosing } \\
\text { Spondylitis Disease Activity Index; BASFI, Bath Ankylosing Spondylitis Functional Index; BMI, body mass index; } \\
\text { HAQ, Health Assessment Questionnaire; VAS, visual analog scale; WPAI, Work Productivity and Activity } \\
\text { Impairment questionnaire: general health. } \\
\text { All values are presented as "mean (SD)" unless otherwise stated. Current NSAID use included acetylsalicylic } \\
\text { acid, celecoxib, diclofenac, ibuprofen, meloxicam, naproxen and others. Current biologic use included abatacept, } \\
\text { adalimumab, anakinra, apremilast, certolizumab pegol, etanercept, golimummab, infliximab, rituximab, } \\
\text { secukinumab, tocilizumab and ustekinumab. }\end{array}$} \\
\hline
\end{tabular}

Conclusions: About two-thirds of patients with axSpA were treated with NSAIDs (with or without biologics) and about three-fourths of patients were treated with biologics (with or without NSAIDs) at enrollment. Patients that were already treated with biologics without NSAIDs at enrollment showed better measures of disease activity and PROs compared with the other treatment groups. Future research will assess changes in clinical and disease characteristics over time by treatment subgroup.

References:

[1] Rudwaleit M, et al. Ann Rheum Dis. 2009;68(6):777-783.

Acknowledgements: Corrona, LLC, has been supported through contracted subscriptions in the last 2 years by AbbVie, Amgen, BMS, Crescendo, Eli Lilly and Company, GSK, Horizon Pharma USA, Janssen, Momenta Pharmaceuticals, Novartis, Pfizer, Roche and UCB.

Disclosure of Interest: P. Mease Grant/research support from: Celgene, Novartis, AbbVie, Amgen, BMS, Lilly, Pfizer, UCB, Consultant for: Celgene, Corrona, 